\title{
Dietary fat and insulin action in humans
}

\author{
Bengt Vessby \\ Unit for Clinical Nutrition Research, Department of Public Health and Caring Sciences/Geriatrics, University of Uppsala, \\ Box 609, SE-75125, Uppsala, Sweden
}

\begin{abstract}
A high intake of fat may increase the risk of obesity. Obesity, especially abdominal obesity, is an important determinant of the risk of developing insulin resistance and non-insulin-dependent diabetes mellitus. It is suggested that a high proportion of fat in the diet is associated with impaired insulin sensitivity and an increased risk of developing diabetes, independent of obesity and body fat localization, and that this risk may be influenced by the type of fatty acids in the diet. Cross-sectional studies show significant relationships between the serum lipid fatty acid composition, which at least partly mirrors the quality of the fatty acids in the diet, and insulin sensitivity. Insulin resistance, and disorders characterized by insulin resistance, are associated with a specific fatty acid pattern of the serum lipids with increased proportions of palmitic $(16: 0)$ and palmitoleic acids (16:1 n-7) and reduced levels of linoleic acid $(18: 2 n-6)$. The metabolism of linoleic acid seems to be disturbed with increased proportions of dihomo-gamma linolenic acid (20:3n-6) and a reduced activity of the $\Delta 5$ desaturase, while the activities of the $\Delta 9$ and $\Delta 6$ desaturases appear to be increased. The skeletal muscle is the main determinant of insulin sensitivity. Several studies have shown that the fatty acid composition of the phosholipids of the skeletal muscle cell membranes is closely related to insulin sensitivity. An increased saturation of the membrane fatty acids and a reduced activity of $\Delta 5$ desaturase have been associated with insulin resistance. There are several possible mechanisms which could explain this relationship. The fatty acid composition of the lipids in serum and muscle is influenced by diet, but also by the degree of physical activity, genetic disposition, and possibly fetal undernutrition. However, controlled dietary intervention studies in humans investigating the effects of different types of fatty acids on insulin sensitivity have so far been negative.
\end{abstract}

Diet: Fatty acids: Insulin sensitivity: Obesity: Palmitic acid: $\Delta 5$ desaturase

\section{Introduction}

The prevalence of obesity, insulin resistance and noninsulin-dependent diabetes mellitus (NIDDM) is rapidly increasing worldwide, with major consequences for community health and demand for medical care. The rapid change indicates that environmental factors, in addition to genetic disposition, are of major importance for the development. The most important lifestyle factors associated with the development of insulin resistance and NIDDM are probably dietary habits and physical activity.

\section{Dietary fat, obesity and insulin resistance}

Obesity, especially abdominal obesity, appears to be the most important determinant of the risk of developing insulin resistance and NIDDM (Ohlsson et al. 1985). There are indications from cross-sectional and dietary intervention studies in humans that a high intake of fat may contribute to the development of obesity (Astrup et al. 2000). There are also indications from some studies that a high intake of fat is associated with impaired insulin sensitivity (Lovejoy \& DiGirolamo 1992; Mayer et al. 1993; Parker et al. 1993; Marshall et al. 1997; Mayer-Davis et al. 1997) and an increased risk of developing diabetes (Marshall et al. 1991, 1994; Tsunehara et al. 1991), also independent of obesity. This risk may be modulated by the type of fatty acids in the diet (Marshall et al. 1991; Tsunehara et al. 1991; Colditz et al. 1992). Several studies indicate that a high-fat diet may be especially deleterious in physically inactive, sedentary individuals (Marshall et al. 1991; Mayer et al. 1993; Mayer-Davis et al. 1997). Obese subjects who are physically active do not experience the same risk.

This review concentrates mainly on what we know about the relationships between dietary fat quality, i.e. the type of dietary fatty acids in the diet, and insulin action in humans. 


\section{Fatty acid composition of human tissues as a dietary marker}

The methods used for estimating diet composition among free living populations are far from perfect. Thus we know that most persons tend to underestimate their energy intake, and that this underestimation is most pronounced among obese people (Blundell \& Cooling, 2000; Lissner et al., 2000). There are also suggestions that some nutrients or food components may be selectively underestimated, e.g. the amount of dietary fat (Lissner et al., 2000). In a search for more reliable dietary markers it has been shown that the fatty acid composition of serum lipid esters (Ma et al. 1995; Nikkari et al. 1995) or adipose tissue triglycerides (Van Staveren et al. 1986; Wolk et al. 1998) mirrors the fatty acid pattern of the diet over several weeks (serum) or many months (adipose tissue) preceding the analysis. This is especially true for the proportions of the polyunsaturated, essential fatty acids, but also to some extent for the saturated fatty acids. A high proportion of these fatty acids in body tissues reflects a high dietary intake during the period before the sample was taken.

\section{Fatty acid composition in serum and insulin sensitivity}

When newly detected NIDDM patients were investigated and compared with healthy controls, they had considerably higher proportions of saturated fatty acids and lower proportions of linoleic acid in the serum cholesterol esters (Salomaa et al. 1990). Subjects with glucose intolerance showed an intermediate situation. A similar picture was observed among 70-year-old men (Table 1) when the fatty acid patterns of serum cholesterol esters were related to insulin sensitivity, as measured by the hyperinsulinaemic, euglycaemic clamp technique (Vessby et al. 1994b). Thus insulin sensitivity was associated with low proportions of palmitic (16:0) and palmitoleic (16:1 n-7) acids and a high proportion of linoleic acid (18:2n-6). The proportions of gamma linolenic $(18: 3 n-6)$ and dihomo-gamma linolenic

Table 1. Relationships (linear correlation coefficients) between insulin sensitivity measured by the euglycaemic, hyperinsulinaemic clamp technique, and fatty acid composition (\%) in serum cholesterol esters (S-CE) and adipose tissue triglycerides (AT-TG), in 70-year-old men

\begin{tabular}{|c|c|c|}
\hline Fatty acid & $\begin{array}{c}\text { S-CE } \\
(N=579)\end{array}$ & $\begin{array}{c}\text { AT-TG } \\
(N=309)\end{array}$ \\
\hline $\begin{array}{l}16: 0 \\
16: 1 n-7 \\
18: 0 \\
18: 1 n-9 \\
18: 2 n-6 \\
18: 3 n-3 \\
18: 3 n-6 \\
20: 3 n-6 \\
20: 4 n-6 \\
20: 5 n-3 \\
22: 4 n-6 \\
22: 5 n-3 \\
22: 6 n-3 \\
16: 1 / 16: 0 \\
18: 3 n-6 / 18: 2 n-6 \\
20: 4 n-6 / 20: 3 n-6\end{array}$ & 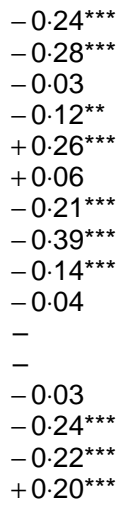 & $\begin{array}{l}-0.16^{\star *} \\
-0.16^{\star} \\
+0.36^{\star \star \star} \\
+0.06 \\
+0.11^{\star} \\
+0.19^{\star \star \star} \\
+0.08 \\
-0.35^{\star \star \star} \\
-0.46^{\star \star \star} \\
-0.20^{\star \star \star} \\
-0.47^{\star \star \star} \\
-0.38^{\star \star \star} \\
-0.21^{\star \star \star} \\
-0.08 \\
0.00 \\
-0.08\end{array}$ \\
\hline
\end{tabular}

${ }^{*},{ }^{* *},{ }^{* *}=P<0.05,0.001$ and 0.001 , respectively.
$(20: 3 n-6)$ acids, which are metabolites of linoleic acid in the insulin-sensitive subjects, were low. The fatty acid pattern in serum lipids in the insulin-resistant subjects suggested a decreased activity of the enzyme $\Delta 5$ desaturase, as evaluated from the ratio between archidonic acid $(20: 4$ $n$-6) and dihomo-gamma linolenic acid (20:3 n-6) and higher activities of $\Delta 6$ desaturase (18:3n-6/18:2 n-6) and $\Delta 9$ desaturase $(16: 1 n-7 / 16: 0)$ than among healthy controls. Partly similar relationships were seen between the fatty acid composition of the adipose tissue triglycerides and insulin sensitivity (Table 1), but there were also clear differences when compared with serum, for example regarding the associations between the proportions of long-chain unsaturated $n-3$ fatty acids and insulin sensitivity. The reason for these discrepancies are at present not clearly understood.

The changes in the fatty acid pattern among insulin resistant or diabetic subjects indicated that they may have had an altered dietary fat composition, compared to healthy people. Another possibility is that the fatty acid changes may be secondary to the metabolic derangement, for example to the diabetic state. However, when healthy 50-year-old men, who later developed NIDDM during a 19-year follow-up period, were compared with men of the same age who remained healthy, they displayed a fatty acid pattern of the same type as seen in glucose-intolerant and diabetic subjects (Vessby et al. 1994a), contradicting the idea that the different fatty acid proportions were consequences of the disease process as such. A similar fatty acid pattern was seen in patients with ischaemic heart disease (Öhrvall et al. $1996 b$ ), who are often characterized by some degree of insulin resistance. Healthy 50-year-old men who later developed myocardial infarction differed from those who remained healthy in that they had a fatty acid profile in serum cholesterol esters characterized by an increased proportion of saturated fatty acids, palmitoleic acid and dihomo-gamma linolenic acid, and low levels of linoleic acid, the same pattern as seen in other insulin-resistant states. The apparent $\Delta 5$ desaturase activity was reduced and also remained an independent risk factor for myocardial infarction when other conventional risk factors were taken into account in the analysis (Öhrvall et al. 1996a).

Thus insulin resistance and related disorders are characterized by specific changes of the proportions of the fatty acid pattern of the serum lipids, indicating possible changes of the activities of the enzymes responsible for desaturation and elongation in the body. These enzyme activities are today recognized to be at least partly regulated by dietary fatty acids (Clarke, 2000). If the dietary fat composition is changed from more saturated to more unsaturated fatty acids during strictly controlled isoenergetic studies where other nutrients are kept constant, the fatty acid proportions change in serum from a pattern characteristic for insulin resistance on the saturated fat diet to one which has been associated with a better insulin sensitivity (on the unsaturated fat diet) (Laserre et al. 1985).

\section{Fatty acid composition of the skeletal muscle and insulin sensitivity}

The peripheral insulin sensitivity is mainly determined by 
the degree of insulin-stimulated glucose uptake in the skeletal muscles. Borkman and co-workers (Borkman et al. 1993) were the first to demonstrate an association between the fatty acid composition of the phospholipids in the skeletal muscle cell membranes and insulin sensitivity in humans. They showed that the insulin sensitivity in healthy Australian men was directly related to the sum of the proportions of long-chain polyunsaturated fatty acids with 20-22 carbon atoms in the skeletal muscle phospholipids. A strong positive association was demonstrated between the apparent activity of $\Delta-5$ desaturase and insulin sensitivity as measured by the clamp technique. In another study in Pima Indians (Pan et al. 1995), similar results were achieved. It has been suggested that the $n-6: n-3$ ratio might be important in determining insulin sensitivity (Storlien et al. 1996). In our study of 70-year-old men in Uppsala (Vessby et al. 1994b) we showed that the proportion of palmitic acid in the skeletal muscle phospholipids was strongly and independently inversely related to insulin sensitivity. There were no significant relationships between the proportions of longchain fatty acids with $20-22$ carbon atoms or the proportions of $n-3$ fatty acids and insulin sensitivity in this material of elderly men. The diverging findings in the three groups of men may to some part be explained by different amounts of $n-3$ fatty acids, or different ratios between $n-6$ and $n-3$ fatty acids, in the skeletal muscles in the three groups. The highest proportions of $n-3$ fatty acids in the three populations were seen among the men fom Uppsala, the lowest in the Pima Indians, and intermediate levels in the Australian men.

The fatty acid composition of the skeletal muscle is influenced by diet, but also by the degree of physical activity (Andersson et al. 1998) and of the muscle fibre composition (Lillioja et al. 1987), factors which are also related to the peripheral insulin sensitivity. The fatty acid composition in the muscle may be modulated by increased physical activity, also with unchanged dietary fat quality, indicating that the metabolism and incorporation of fatty acids in the membrane phospholipids is influenced by the degree of physical activity as such. The differences in fatty acid composition between trained and untrained subjects, with a pattern indicating an improved insulin sensitivity in the former group, are also significant when adjusted for muscle fibre composition (A. Andersson et al., unpublished results).

\section{Reasons for variations in the fatty acid pattern of skeletal muscles}

The fatty acid composition of the skeletal muscles changes with the the fatty acid composition of the diet. This was demonstrated in experimental studies in animals (Ayre \& Hulbert, 1996). In a recent human study we could show high levels of saturated fatty acids in the muscles of people who had been on a strictly controlled, butter-rich diet for 3 months. Subjects who had been on an identical diet containing rape seed oil showed lower levels of saturated fatty acids but significantly higher proportions of oleic acid (B. Vessby et al., unpublished results). The effect of dietary fat may be influenced by the degree of physical activity, which may also indirectly modify the fatty acid composition of the skeletal muscles by modifying the muscle fibre composition. To what extent the variations in fatty acid composition are due to environmental effects, or secondary to genetic variations in the activities of the enzymes regulating the desaturation and elongation of the fatty acids in the body, or due to skeletal muscle fibre composition, is presently unknown. In addition, it has been suggested that a reduction of the activity of the $\Delta-5$ desaturase may be an effect of fetal undernutrition (Ozanne et al. 1998), with possible consequences for the fatty acid composition and insulin sensitivity in adult life.

\section{Why may variations in skeletal muscle fatty acid composition affect insulin sensitivity?}

A detailed analysis of how variations of the fatty acid composition of the cell membrane may affect insulin sensitivity falls outside the scope of this review. Several explanations are possible, as discussed earlier (Storlien et al. 1996). Altered fatty acid composition of the cell membranes in the skeletal muscle will influence the physicochemical properties of the membranes with consequent effects, for example on receptor function, ion transport over the membranes, cell energy requirement and cell signalling. A high proportion of saturated fatty acids in the cell membrane may impair insulin action by:

(1) altered insulin receptor binding/affinity

(2) altered ability to translocate/insert glucose transporters

(3) changes of phospholipid fatty acids - interaction with function of second messenger (protein kinase C)

(4) reduced ion permeability (membranes less 'leaky').

\section{Intervention studies in humans}

If the dietary fatty acid composition is a significant determinant of insulin sensitivity, it should be possible to influence insulin sensitivity by changing the fatty acid composition of the diet. A number of dietary studies have been performed during recent years, with the aim of investigating this issue. Trial design and duration, inclusion criteria, methodology and type of dietary modifications undertaken have differed. In some studies not only the type of fat, but also the relation between the proportions of fat and carbohydrates, have been changed. In other studies the energy intake has varied during the test periods, causing variations in body weight which may have influenced the results. If certain criteria have to be fulfilled (isoenergetic, randomized, controlled trials where insulin sensitivity has been evaluated by adequate methodology the euglycaemic hyperinsulinaemic clamp technique, De Fronzo et al. 1979; the frequently sampled intravenous glucose tolerance test; or the 'minimal model' according to Bergman, see Steil et al. 1993), and the overview is restricted to investigations of the effects of a change of fat quality only, then only a few studies fulfil these criteria.

Studies in healthy subjects comparing the effects of changes of dietary fatty acids on insulin sensitivity (Table 2) have uniformly shown negative results, as did a placebocontrolled study of the effects of supplementation with $n-3$ fatty acids in hypertensive subjects. Also, when measures of insulin secretion were evaluated no significant changes were 
Table 2. Effects of a change of dietary fatty acid composition on insulin action in non-diabetic subjects - controlled studies

\begin{tabular}{|c|c|c|c|c|c|}
\hline Study & Subjects & Trial design & $\begin{array}{l}\text { Duration } \\
\text { (weeks) }\end{array}$ & End point & Outcome \\
\hline Schwab et al. 1995 & 15 healthy $f$ & $\begin{array}{l}\text { High palmitic-acid-high I } \\
\text { auric-acid diets. Random } \\
\text { crossover }\end{array}$ & $2 \times 4$ & FSIGT & No change \\
\hline Fasching et al. 1996 & 8 healthy $\mathrm{m}$ & $\begin{array}{l}\text { SAFA-MUFA- } n-6 \text { PUFA } \\
\text { diets. Short-term, random } \\
\text { crossover }\end{array}$ & $3 \times 1$ & $\begin{array}{l}\text { FSIGT } \\
\text { Clamp }\end{array}$ & $\begin{array}{l}\text { No change } \\
\text { No change }\end{array}$ \\
\hline Louheranta et al. 1998 & 15 healthy $f$ & $\begin{array}{l}\text { High stearic-acid-high } \\
\text { oleic-acid diets. Random } \\
\text { crossover }\end{array}$ & $2 \times 4$ & FSIGT & No change \\
\hline Louheranta et al. 1999 & 14 healthy $f$ & $\begin{array}{l}\text { TFA-MUFA diets. Random } \\
\text { crossover }\end{array}$ & $2 \times 4$ & FSIGT & No change \\
\hline $\begin{array}{l}\text { Vessby et al. } \\
\text { (unpublished results) }\end{array}$ & 20 moderately hyperlip. m/f & $\begin{array}{l}\text { SAFA-rapeseed oil diets. } \\
\text { Random crossover }\end{array}$ & $2 \times 3$ & $\begin{array}{l}\text { IVGTT } \\
\text { Clamp }\end{array}$ & $\begin{array}{l}\text { No change } \\
\text { No change }\end{array}$ \\
\hline Toft et al. 1995 & 78 hypertensives & $\begin{array}{l}\text { Corn oil-fish oil ( } 4 \mathrm{~g} n-3) \\
\text { supplementation. Random, } \\
\text { double-blind, parallel groups }\end{array}$ & 16 & $\begin{array}{l}\text { Clamp } \\
\text { OGTT }\end{array}$ & $\begin{array}{l}\text { No change } \\
\text { No change }\end{array}$ \\
\hline
\end{tabular}

$M=$ males, $f=$ females.

SAFA, TFA, MUFA, PUFA = saturated, trans, monounsaturated and polyunsaturated fatty acids, respectively.

FSIGT = frequently sampled intravenous glucose tolerance test or 'minimal model' according to Bergman (Steil et al. 1993).

Clamp=euglycaemic, hyperisulinaemic clamp technique (De Fronzo et al. 1979).

IVGTT, OGTT = intravenous and oral glucose tolerance test, respectively.

recorded. In NIDDM patients most studies have focused on the effect of supplementation with $n-3$ fatty acids (Table 3 ). Although animal experiments have suggested positive effects of $n-3$ fatty acids on insulin sensitivity, no positive effect on insulin action has hitherto been demonstrated in controlled studies in humans.

\section{Further studies needed}

Based on experimental studies, epidemiology, and clinical trials evaluating the associations between fatty acid composition and insulin sensitivity in humans, it seems reasonable to believe that the dietary fat amount and fat composition, in concert with the degree of physical activity, are among several factors of importance for peripheral insulin sensitivity. To finally prove this point we need to show that a change of dietary fatty acid composition will also affect insulin sensitivity in humans. Nearly all studies to date have been short-term studies involving a restricted number of subjects. It is conceivable that a change of fatty acid pattern in the skeletal muscle phospholipid is a rather slow process over weeks and months, and that most earlier studies may have been too short and/or had too low statistical power to demonstrate a significant effect. Further studies are urgently needed.

The methodology for controlled dietary studies is complex, the variability between individuals with regard to dietary response is large, and the costs for studies of this kind are high. In a recent multi-centre study (Kuopio, Aarhus, Naples, Wollongong and Uppsala), known as the KANWU study, the ambition was to perform a controlled trial of adequate size and duration to evaluate the effect of a change of dietary fat quality on insulin sensitivity and insulin secretion in healthy humans. The study was a controlled, randomized trial over 3 months which was performed simultaneously at the five centres. The preliminary results indicate for the first time that a change of dietary fatty acid composition from more saturated to more monunsaturated

Table 3. Effects of dietary supplementation with fatty acids on insulin action in non-insulin-dependent diabetes (NIDDM) patients - controlled studies

\begin{tabular}{|c|c|c|c|c|c|}
\hline Study & Subjects & Trial design & $\begin{array}{l}\text { Duration } \\
\text { (weeks) }\end{array}$ & End point & Outcome \\
\hline Borkman et al. 1989 & 10 NIDDM & $\begin{array}{l}\text { Fish oil ( } 3 \mathrm{~g} n \text {-3)-placebo. Random } \\
\text { crossover }\end{array}$ & $2 \times 3$ & Clamp & No change \\
\hline Annuzzi et al. 1991 & 8 NIDDM & 3 g n-3-placebo. Random crossover & $2 \times 2$ & Clamp & No change \\
\hline Boberg et al. 1992 & 14 NIDDM & $\begin{array}{l}\text { Fish oil (3g } n \text {-3)-placebo. Random } \\
\text { crossover }\end{array}$ & $2 \times 8$ & Clamp & No change \\
\hline McManus et al. 1996 & 11 NIDDM & $\begin{array}{l}\text { Linseed oil ( } 3 \mathrm{~g} n \text {-3)-fish oil }(3 \mathrm{~g} n-3)- \\
\text { placebo. Random crossover }\end{array}$ & $3 \times 12$ & FSIGT & No change \\
\hline Lou et al. 1998 & 12 NIDDM & $\begin{array}{l}6 \mathrm{~g} \text { fish oil or sunflower oil. } \\
\text { Random crossover }\end{array}$ & $2 \times 8$ & Clamp & No change \\
\hline
\end{tabular}

For abbrevations see Table 2. 
fatty acids is associated with improved insulin sensitivity in humans (Vessby et al. 1999).

\section{References}

Andersson A, Sjödin A, Olsson R \& Vessby B (1998) Effects of physical exercise on phospholipid fatty acid composition in skeletal muscle. American Journal of Physiology 274 (Endocrinologi and Metabolism 37), E432-E438.

Annuzzi G, Rivellese A, Capaldo BD, Marino L, Marotta G \& Riccardi G (1991) A controlled study on the effects of $n-3$ fatty acids on lipid and glucose metabolism in non-insulin-dependent diabetic patients. Atherosclerosis 87, 65-73.

Astrup A, Ryan L, Grunwald GK, Storgaard M, Saris W, Melanson E \& Hill JO (2000) The role of dietary fat in body fatness: evidence from a preliminary meta-analysis of ad libitum low-fat dietary intervention. British Journal of Nutrition 83 (Suppl. 1), S25-S32.

Ayre KJ \& Hulbert AJ (1996) Dietary fatty acid profile influences the composition of skeletal muscle phospholipids in rats. Journal of Nutrition 126, 653-662.

Blundell JE \& Cooling J (2000) Routes to obesity: phenotypes, food choices and activity. British Journal of Nutrition 83 (Suppl. 1), $\mathrm{S} 33-\mathrm{S} 38$.

Boberg M, Pollare T, Siegbahn A \& Vessby B (1992) Supplementation with $n-3$ fatty acids reduces triglycerides but increases PAI-1 in non-insulin-dependent diabetes mellitus. European Journal of Clinical Investigation 22, 645-650.

Borkman M, Chisholm DJ, Furler SM, Storlien LH, Kraegen EW, Simons LA \& Chesterman CN (1989) Effects of fish oil supplementation on glucose and lipid metabolism in NIDDM. Diabetes 38, 1314-1319.

Borkman M, Storlien LH, Pan DA, Jenkins AB, Chisholm DJ \& Campbell LB (1993) The relationship between insulin sensitivity and the fatty acid composition of skeletal-muscle phospholipids. New England Journal of Medicine 328, 238-244.

Clarke SD (2000) Polyunsaturated fatty acid regulation of gene transcription: a mechanism to improve energy balance and insulin resistance. British Journal of Nutrition 83 (Suppl. 1), S59-S66.

Colditz GA, Manson JE, Stampfer MJ, Rosner B, WillettWC \& Seizer FE (1992) Diet and risk of clinical diabetes in women. American Journal of Clinical Nutrition 55, 1018-1023.

De Fronzo RA, Tobin JD \& Andres R (1979) Glucose clamp technique, a method for quantifying insulin secretion and resistance. American Journal of Physiology 237, 214-233.

Fasching P, Ratheiser K, Schneeweiss B, Rohac M, Nowotny P \& Waldhausl W (1996) No effect of short-term dietary supplementation of saturated and poly- and monounsaturated fatty acids on insulin secretion and sensitivity in healthy men. Annals of Nutrition and Metabolism 40, 116-122.

Laserre M, Mendy F, Spielmann D \& Jacotot B (1985) Effects of different dietary intake of essential fatty acids on C 20,3n-6 and C 20, 4 n-6 levels in human adults. Lipids 20, 227-233.

Lillioja S, Young AA, Culter CL, Ivy JL, Abbott WG, Zawadzki JK, Yki-Jarvinen H, Christin L, Secomb TW \& Bogardus C (1987) Skeletal muscle capillary density and fiber type are possible determinants of in vivo insulin resistance in man. Journal of Clinical Investigation 80, 415-424.

Lissner L, Heitmann BL \& Bengtsson C (2000) Population studies of diet and obesity. British Journal of Nutrition 83 (Suppl. 1), $\mathrm{S} 21-\mathrm{S} 24$

Lou J, Rizkalla SW, Vidal H, Oppert JM, Colas C, Boussari A, Gurre-Millo M, Chapuis AS, Chevalier A, Durand G \& Slama G (1998) Moderate intake of $n-3$ fatty acids for 2 months has no detrimental effect on glucose metabolism and could ameliorate the lipid profile in type 2 diabetic men. Results of a controlled study. Diabetes Care 21, 717-724.

Louheranta AM, Turpeinen AK, Schwab US, Vidgren HM, Parviainen MT \& Uusitupa MI (1998) A high-stearic acid diet does not impair glucose tolerance and insulin sensitivity in healthy women. Metabolism 47, 529-534.

Louheranta AM, Turpeinen AK, Vidgren HM, Schwab US \& Uusitupa MI (1999) A high-trans fatty acid diet and insulin sensitivity in young healthy women. Metabolism 48, 870-875.

Lovejoy J \& DiGirolamo M (1992) Habitual dietary intake and insulin sensitivity in lean and obese adults. American Journal of Clinical Nutrition 55, 1174-1179.

Ma J, Folsom AR, Eckfelt JH, Lewis L \& Chambless LE, the Atherosclerosis Risk In Communities (ARIC) Study Investigators (1995) Short- and long-term repeatability of fatty acid compositionof human plasma phospholipids and cholesterol esters. American Journal of Clinical Nutrition 62, 572-578.

Marshall JA, Hamman RF \& Baxter J (1991) High-fat, low carbohydrate diet and the etiology of non-insulin-dependent diabetes melltus. The San Luis Valley Diabetes Study. American Journal of Epidemiology 134, 590-603.

Marshall JA, Hoag S, Shetterley S \& Hamman RF (1994) Dietary fat redicts conversion from impaired glucose tolerance to NIDDM The San Luis Valley Diabetes Study. Diabetes Care 17, 50-56.

Marshall JA, Bessesen SH \& Hamman RF (1997) High saturated fat and low starch and fibre are are associated with hyperinsulinaemia in a non-diabetic population - The San Luis Valley Diabetes Study. Diabetologia 40, 430-438.

Mayer EJ, Newman B, Quesenberry CP Jr \& Selby JV (1993) Usual dietary fat intake and insulin concentrations in healthy women twins. Diabetes Care 16, 1459-1469.

Mayer-Davis J, Monaco JH, Hoen HM, Carmichael S, Vitolins MZ, Rewers MJ, Haffner SM, Ayad MF, Bergman RN \& Karter AJ (1997) Dietary fat and insulin sensitivity in a triethnic population The role obesitas. The Insulin Resistance Atherosclerosis Study (IRAS). American Journal of Clinical Nutrition 65, 79-87.

McManus RM, Jumpson J, Finegood DT, Clandinin MT \& Ryan EA (1996) A comparison of the effects of $n-3$ fatty acids from linseed oil and fish oil in well controlled type II diabetes. Diabetes Care 19, 463-476.

Nikkari T, Lukkainen P, Pietinen P \& Puska P (1995) Fatty acid composition of serum lipid fractions in relation to gender and quality of dietary fat. Annals of Medicine 27, 491-498.

Ohlsson LO, Larsson B, Svärdsudd K, Welin L, Eriksson H, Wilhelmsen L, Björntorp P \& Tibblin G (1985) The influence of body fat distribution on the incidence of diabetes mellitus, 13.5 year follow-up of the participants in the study of men born 1913. Diabetes 34, 1055-1058.

Öhrvall M, Berglund L, Salminen I, Lithell H, Aro A \& Vessby B (1996) The serum cholesterol ester fatty acid composition but not the serum concentration of alpha tocopherol predicts the development of myocardial infarction in 50-year-old men, 19 years follow up. Atherosclerosis 127, 65-71.

Öhrvall M, Sundlöf G \& Vessby B (1996) Gamma, but not alpha, tocopherol levels in serum are reduced in coronary heart disease patients. Journal of Internal Medicine 239, 111-117.

Ozanne SE, Martensz ND, Petry CJ, Loizou CL, Hales CN (1998) Maternal low protein diet in rats programmes fatty acid desaturase activities in the offspring. Diabetologia 41, 1337-1342.

Pan DA, Lillioja S, Milner MR, Kriketos AD, Baur LA, Bogardus C \& Storlien LH (1995) Skeletal muscle membrane lipid composition is related to adiposity and insulin action. Journal of Clinical Investigation 96, 2802-2808.

Parker DR, Weiss ST, Troisi R, Cassano PA, Vokones PS \& Landsberg L (1993) Relationship of dietary saturated fatty acids and body habitus to serum insulin concentrations, the normative 
aging study. American Journal of Clinical Nutrition 58, 129136.

Salomaa V, Ahola I, Toumilehto J, Aro A, Pietinen P, Korhonen PJ \& Pentilä I (1990) Fatty acid compsition of serum cholesterol esters in different degree of glucose intolerance. Metabolism 39, $1285-1291$.

Schwab US, Niskanen LK, Maliranta HM, Savolainen MJ, Kesaniemi YA \& Uusitupa MI (1995) Lauric and palmitic acidenriched diets have minimal impact on serum lipid and lipoprotein concentrations and glucose metabolism in healthy women. Journal of Nutrition 125, 466-473.

Steil GM, Volund A, Kahn SE \& Bergman RN (1993) Reduced sample number for calculation of insulin sensitivity and glucose effectiveness from the minimal model. Suitability for use in population studies. Diabetes 42, 250-256.

Storlien LH, Pan DA, Kriketos AD, Connor JO, Caterson ID, Coney GJ, Jenkins AB \& Baur LA (1996) Skeletal muscle membrane lipids and insulin resistance. Lipids 31, S261-S265.

Toft I, Bonaa K, Ingebretsen OC, Nordoy A \& Jenssen T (1995) Effects of $n-3$ polyunsaturated fatty acids on glucose homeostasis and blood pressure in essential hypertension. A randomized, controlled trial. Annals of Internal Medicine 123, 911-918.
Tsunehara CH, Leonetti DL \& Fujimoto WY (1991) Animal fat and cholesterol intake is high in men with IGT progressing to NIDDM. Diabetes 40 (Suppl.), 427A (abstr.)

Van Staveren WA, Deurenberg P, Katan MB, Durema J, de Groot LCPGM \& Hoffmans MDAF (1986) Validity of the fatty acid composition of subcutaneous adipose tissue microbiopsies as an estimate of the diet of separate individuals. American Journal of Epidemiology 123, 455-463.

Vessby B, Aro A, Skarfors E, Berglund L, Salminen I \& Lithell H (1994a) The risk to develop NIDDM is related to the fatty acid composition of the serum cholesterol esters. Diabetes 43, 13531357.

Vessby B, Tengblad S \& Lithell H (1994b) The insulin sensitivity is related to the fattty acid composition of the serum lipids and the skeletal muscle phospholipids in 70 year old men. Diabetologia 37, 1044-1050.

Vessby B et al. for the KANWU Study Group (1999) Effects of dietary fat on insulin sensitivity and insulin secretion - the KANWU study. Diabetologia 42 (Suppl. 1), A46 (abstr.).

Wolk A, Vessby B, Ljung H \& Barrefors P (1998) Evaluation of a biologic marker of dairy fat intake. American Journal of Clinical Nutrition 68, 291-295. 